Canadian Journal of Family and Youth, 13(3), 2021, pp. 236-240

ISSN 1718-9748@ University of Alberta

http://ejournals, library,ualberta.ca/index/php/cify

\title{
Wong, Lindsay. (2018). The Woo-Woo: How I Survived Ice Hockey, Drug Raids, Demons, and My Crazy Chinese Family. Vancouver: Arsenal Pulp Press.
}

Reviewed by: Jojo Boateng, MacEwan University

Lindsay Wong's book, "The Woo-Woo: How I survived Ice Hockey, Drug Raids, Demons, and my Crazy Chinese Family," is a fascinating memoir that sheds light on the struggles of a young Asian Canadian as she is forced to adhere to traditional values that she knows will lead to her demise, while actively denouncing help from the outside world. In her memoir, Wong begins at the end, showing the reader where she currently is in life and making them ask the question: Why is she acting this way and what happened in her life? Wong then opens the door into her childhood, showing us the experiences she wished to escape. In doing so, Wong allows the readers to see to the eerie side of the Asian Canadian experience and answers the question we asked initially. Throughout the chapters, Wong introduces and builds upon the smaller themes of superstition, fear and running away, and broken relations, which stem from the overarching theme of mental illness.

Wong does not define mental illness in the way Western society has become accustomed to, instead, she defines mental illness as "seventeenth-century Chinese psychobabble." (p. 24), which states mental illness does not exist. Rather people become unstable due to demonic possessions. In other words, Wong and her family do not see mental illness as a medical condition. They see it as an individual becoming possessed by the Woo-Woo - Chinese ghosts. The overarching theme 
of mental illness is seen from the beginning to the end of the book, but this theme is never presented alone. The smaller theme of superstition is always present to integrate the family's belief system. For example, on pages 103-109, we see a clear example of how the Wong family adheres to the traditional belief that abnormal behavior results from demonic possession. In these pages, Wong and her mother visit Poh-Poh (Wong's grandmother), who believes the fridge is electrocuting her.

While Wong and her mother believe this is another demonic possession, a concerned family member brings Poh-Poh to a psychiatrist. After the visit, she is prescribed lithium and clozapine, and it is decided Wong's mother would be responsible for looking after Poh-Poh "as she fought off what everybody called her 'demonic possession'" (p. 105). One night after dinner, Wong's mother does what she describes as "helping your lazy grandmother" (p. 107) by throwing away Poh-Poh's medication. She justifies her actions by saying, "These kinds of doctors don't believe in ghosts. They think Poh-Poh is crazy, but they can't see that she's possessed! The medication hides the demons" (p. 109). This results in Poh-Poh becoming paranoid about the world once again. The Wong family's adherence to traditional values causes them to reject the ideas presented within Western medicine, specifically those related to mental health. This causes the family to be incapable of caring for themselves or others. The rejection of Western medicine becomes one of the struggles Wong must face as she becomes aware that she is a product of the Woo-Woo, no matter how Westernized she becomes or how far she runs. Essentially, Wong's world is ruled by the fear of being visited by the Woo-Woo; this fear stems from the superstitious thinking that surrounds the idea of mental health. To cope with this fear, Wong and her family adopt dysfunctional tendencies to escape from their reality. 
In the book, Wong introduces the interrelated ideas of fear and running away as a means of escaping from the demonic possession of the Woo-Woo. Wong explains that she grew up in a house where unexpected outbursts and other eccentric behaviour were "downplayed as the WooWoo's fault" (p. 21) and were dealt with by running away. The first example the reader is given of this occurs when Wong's parents get into an argument, resulting in an outburst by her mother and her father running away. As a result, from a young age, Wong is exposed to avoidant behaviour. Through her parents' demonstrations, she is taught to run from experiences that scare her instead of trying to understand them. In other words, Wong has been introduced to the idea that avoiding fearful situations is an appropriate way of dealing with her issues. For example, When Wong is six years old, her mother uses a shopping center as a means of avoiding "supernatural problems at home" (p. 25).

This fearful and avoidant nature is manifested through the family's inability to recognize the unbalanced behaviour presented through Poh-Poh, Quiet Snow, and Beautiful One is not the result of demonic possession but rather the result of untreated mental illness. As the chapters continue, we delve deeper into the dysfunctional tendencies that are developed by the family's fear of being possessed and the avoidance of situations that are Woo-Woo related, focusing on specifically how they manifest in Wong, herself. The manifestation of fear and avoidance presented in Wong is a direct reflection of that of her parents. Wong follows the example that her parents have put forward, most notably reflected in Chapter Twelve. When Wong flies to Europe with a friend to avoid thinking about Beautiful One trying to kill herself at her cousin's wedding (p.233), we can see that 
Wong is following the practices that she has been exposed to at home. She uses Europe as a means of escaping the "supernatural problems at home" (p. 25). The ideas of fear and avoidance are the basis of which the Wong family's dysfunctional tendencies are created. These ideas are related to the theme of mental health, as they lead to the destruction of relationships.

As a result of the avoidant nature the Wong family has adopted to deal with uncomfortable situations, they cannot effectively communicate their emotions, specifically their fears, without being ridiculed and dismissed. Wong describes emotional displays as an equivalent of "begging on the street, [which is] a burden for everyone." (p. 68) This uncaring dismissal of emotion occurs in a vertical transmission between parent and child. For example,

As my sister sobbed non-stop, we were supposed to mock her for crying and not hiding her weakness, for surely, she was headed for a bout of demonic possession, which was like deliberately going outside in the snow without a jacket and catching pneumonia. 'Only idiots cry,' my father explained to my sister, looking ashamed of her... 'I never cry,' he continued, pleased. 'Learn to suffer in silence... People who cry become Woo-Woo' (pp. 67-68).

In addition to the vertical transmission, emotional dismissal also occurs in a horizontal transmission between siblings and cousins. For example, Wong and her cousin's relationship diminishes due to them bitterly competing for Beautiful One's attention. This competition includes hitting, name-calling, and the use of nasty remarks to diminish one another's feelings. By being unsympathetic to others' emotional needs, the same way her father was insensitive to the emotional needs of his youngest daughter. Wong once again reflects the uncaring and traditional practices of her family. These cruel interactions not only produce a wedge in the relationship of parent and 
child but between siblings and cousins as well. The inattentive nature present within Wong's nuclear family and her extended family stems from the avoidant nature the family has adopted when dealing with fearful situations. The relationship between these themes implies the family was so afraid of mental health, they have allowed it to rule their lives and ruin relationships.

While Wong's book sheds light on the looming disintegration resulting from adhering to dysfunctional traditional values, the book left me with the question of who Wong was now. After she came to terms with her impending doom, what new values and traditions did she take on? What coping mechanisms did she use to deal with these past experiences? Other disciplines that may benefit from the book are social work, psychology, and Asian studies, to name a few. "The WooWoo: How I Survived Ice Hockey, Drug Raids, Demons, and My Crazy Chinese Family" was an engaging, easy to read, and enthralling book that was difficult to put down. I would recommend it to anyone interested in mental health and the effects the rearing environment has on individuals. 